\title{
Development of a Web-Based Geographic Information System for Mass Land Valuation: A Case Study of Westlands Constituency, Nairobi County
}

\author{
Godfrey Ludiema*, Godfrey Makokha, Moses Murimi Ngigi \\ Institute of Geomatics, GIS and Remote Sensing (IGGReS), Dedan Kimathi University of Technology, Nyeri, Kenya \\ Email: *goddyludman@gmail.com
}

How to cite this paper: Ludiema, G., Makokha, G. and Ngigi, M.M. (2018) Development of a Web-Based Geographic Information System for Mass Land Valuation: A Case Study of Westlands Constituency, Nairobi County. Journal of Geographic Information System, 10, 283-300. https://doi.org/10.4236/jgis.2018.103015

Received: March 29, 2018

Accepted: June 25, 2018

Published: June 28, 2018

Copyright $\odot 2018$ by authors and Scientific Research Publishing Inc. This work is licensed under the Creative Commons Attribution International License (CC BY 4.0). http://creativecommons.org/licenses/by/4.0/

\section{Open Access}

\begin{abstract}
The development of a web-based Geographic Information System for mass property valuation was the main focus of this research. The developed web GIS allows effective dissemination, extraction and analysis of mass land valuation information over the Internet. It also allows for automation of the mass property valuation process by compiling a centralized mass valuation roll database. The Westlands Constituency, one of the administrative regions of the Nairobi City County was used as a case study. The research focused on automation of the mass property valuation roll by creating a centralized database that is accessible by all users on the web-based GIS portal. This was done by customizing and integrating a web-based GIS system based on open source QuantumGIS, GeoServer and PostgreSQL/PostGIS as a relational database. Leaflets APIs were used for the development of an interactive and friendly geographic user interface. The developed system enables users to view and interact with the spatial data. This improves the efficiency and effectiveness of the decision making process and data sharing for mass property valuation and optimal property taxation purposes.
\end{abstract}

\section{Keywords}

Open Source, Geographic Information Systems, Property Valuation, Spatial Database

\section{Introduction}

Ever rising urbanization offers opportunities for the development of real estate market that calls for an efficient property valuation approach to prepare an 
up-to-date mass valuation roll for optimal property taxation [1]. However, accurate assessment of property values has been difficult for a very long time [2]. Property assessors rely on access to comprehensive, reliable and timely evidence of recent property transactions in order to make informed predictions of the mass property value [3]. Legislative restrictions on data release to the public, confidentiality constraints and conservative attitudes hinder data accessibility within the Nairobi County property market enable efficient and regular property assessment. Availability of a central sales register and confidentiality of land information facilitates property valuation by the county authority for the purposes of property taxation based on their property values. It is also a constitutional requirement in the Kenyan constitution valuation for rating Act Cap-266 laws of Kenya that allows the preparation of the mass valuation roll after every 10 years so as to generate the significant revenue from these properties [4]. However, this has not been the case for Nairobi City County which continues to rely on a mass valuation roll that was last prepared and updated in 1980. This may have been due to lack of resources to prepare an up-to-date mass valuation roll on regular basis. Efficient and effective preparation of the mass valuation roll and subsequent optimal land taxation depends upon the availability of quality and correct land attributes information [5].

Mass property valuation may be assessed using the available traditional valuation methods such as comparative methods, cost methods and interactive analysis method which may be exhaustive, time-consuming, inaccurate and characterized with data inconsistency [6]. As such, there is a growing need to develop alternative valuation approaches capable of estimating property values of large numbers in an economical way based on geographical information systems that are able to represent spatial urban dynamics and development [7]. However, these methods become effective and efficient when integrated into a Geographic Information System that automates data management of property sales transactions in the preparation of the mass valuation roll and hence full automation of mass property valuation [8].

There is a need for a spatially enabled Integrated County Information System (ICIS) database for Nairobi City County into which all information about a property is collected from all sources and compiled into an up-to-date property mass valuation roll. All information about all ratable owner and property should be maintained in a reliable way by designing a mass valuation system in a holistic way. This system should also be the centralized, web-based, role-based multi-user system, where all users have their own login and roles to access various components of the web GIS system.

The development of the prototype for a GIS-based mass land valuation roll for Westlands Constituency was achieved by setting out a general objective that was to develop a Web-based GIS for mass land valuation for Westlands Constituency. The research was also guided by specific objectives that aimed;

- To create a centralized spatial database for land parcels in Westlands constituency that identifies the ownership of each piece of real property. 
- To establish a web map for owner ratable properties in the mass valuation roll for Westlands constituency.

- To establish an automated web-based GIS mass land valuation roll for property taxation purposes and revenues collection.

The developed system can be accessed on the internet browser using various electronic devices like the computers, tablets and smart phones. The system developed can be accessible by multiple users at ago unlike the desktop GIS applications that allow a single user at ago. The system is user friendly and easy to use as compared to desktop GIS application that requires professional training and experience.

The novelty of this research was to develop a web-based geographic information system that integrates property valuation with web mapping technologies. The development of a web-based GIS is a new technology in developing countries like Kenya where property valuation has continued to be done using traditional approaches which are inefficient and ineffective in the preparation of a mass valuation roll for optimal property taxation. Due to rapid urbanization in Africa and over reliance on land finance based revenues developing countries, call for a need of automated property valuation approaches so as to obtain an optimal revenue collection from these properties.

\section{The Area of Study}

Westlands Constituency was selected as the study area shown in Figure 1 for this research and is part of Nairobi County Council area. It is situated within Westlands Sub-county with an area of $72.4 \mathrm{~km}^{2}$. It comprises of the high suburb areas such as Lakeview, Highridge, Kitisuru Runda and Muthaiga, as well as slum areas like, Kaptagat, Githogoro, Kangemi, and DeepSea, Mji wa Huruma, Kibagare, Ndumboini, Maasai, and Suswa.

The selected area of study serves diverse rapid urbanization and real estate development ranging from single residential to multiple residential and from multiple residential to multiple commercial developments. The region has higher property values in the real estate markets. The property values in the region are still relative lower compared to the same properties in the CBD. Property investors are heavily investing in the region and as a result land prices are increasing rapidly.

\section{Methods and Materials}

\subsection{Datasets Used}

Table 1 shows the list of all the spatial and non-spatial datasets that were used to develop the prototype for Westlands Constituency. The open source software applications in Table 2 were used in the development and implementation of a web-based GIS application for the study area.

\subsection{User Needs Assessment}

The anticipated Web-based GIS application users needs assessment was carried 


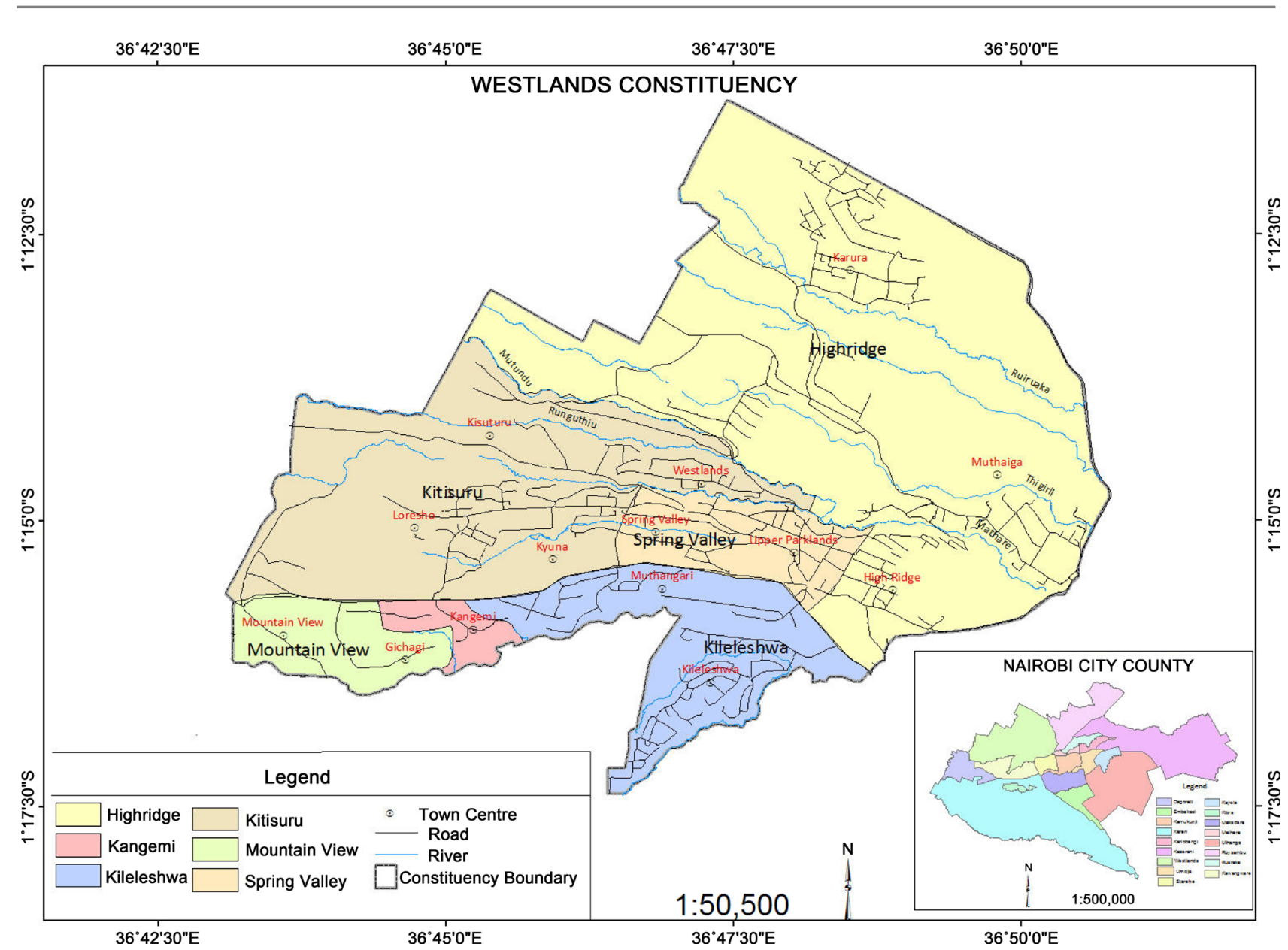

Figure 1. Location of the study area for mass property valuation: Westland constituency, Nairobi city county (Source: Author).

Table 1. Datasets used.

\begin{tabular}{llll}
\hline Datasets & Type & Data Format & Source \\
\hline Land parcel data & primary & Esri shapefile & Nairobi City County \\
Building data & primary & Esri shapefile & Ramani Geo-systems \\
Road data & primary & Esri shapefile & Ramani Geo-systems \\
River data & primary & Esri shapefile & Nairobi City County \\
Estate data & primary & Esri shapefile & Ramani Geo-systems \\
Sales comparables & primary & Excel & National land commission \\
Base maps & online & & Open Street maps \\
\hline
\end{tabular}

Table 2. Open source software applications used.

\begin{tabular}{cc}
\hline Software Application & Function \\
\hline Quantum GIS 2.14 & Spatial data creation and processing \\
PostgreSQL 9.5/ PostGIS 2.3 & Object relational database/Spatial database extension \\
Geoserver 2.11.1 & Data visualization \\
Leaflets APIs libraries & Development of geographic user interface \\
Sublime text editor & Programming platform \\
Xampp server & Creates a local host service
\end{tabular}


out by conducting personal interviews using structured questions. A total of 100 questionnaires were distributed and administered to several staff ranging from the valuation managers, valuation officers, data officers, GIS officers. Out of the 100 questionnaires administered, 80 responses were received back and were used to determine which features they desired to use in the system.

\subsection{Data Collection and Capture}

A large format scanner was used to create a raster data from existing paper map. As the scanning took place the scanned image displayed on the computer screen as a raster digital file was saved ready georefencing. The land parcels datasets were captured through georefencing cadastral plans and digitization using QGIS. The Geographic Valuation Blocks were also captured through digitization of the hard copy valuation zonal maps designated by the Nairobi City County valuation office. The sales comparable datasets were collected from the National Land commission of Kenya in form of hard copy format. They were then entered into an excel tables for easier integration into a geographic information system environment.

\subsection{Preparation of the Mass Valuation Roll}

An inventory of attributes in the valuation roll were populated by data entry process that included rateable owner personal information like owner names and address of location of the property, serial number, map number, land parcel number and size of the parcel, geographic valuation block code, geographic valuation block rate, market value of the property and the Unimproved Site Value (USV). A GIS-based mass valuation roll was generated from the Microsoft access database by importing it into the QGIS 3.0 where it was then joined with the land parcel shapefile dataset using the spatial join tool available in QGIS 3.0.

\subsection{Spatial Data Processing and Manipulation}

Installation of Quantum GIS 3.0 software was done by downloading QGIS 3.0 from the internet [9] and installed in the computer then used to digitize and manipulate data layers for the, property sales comparables, land parcels, roads Geographic Valuation Zones. Hard copy paper maps were scanned using large format scanners and the saved as an image. The scanned image was then georeferenced and digitized into a shapefile format of a land parcels. Quantum GIS was also used to convert tabular data in excel for bulk property valuation roll data figures, property owner information and appurtenances into Esri shapefile format and corresponding attribute data added. Data quality checks were done through data evaluation and validation. A connection to the PostGIS database was configured by inserting the required credentials using a PostGIS plugin available on the QGIS 3.0

\subsection{Spatial Database Creation}

PostgreSQL 9.5 database was installed in the default program files directory and 
customizing the new port to 5433 and a database super password was set for use when accessing the database. A new spatial database for mass valuation roll was created in PostgreSQL using a friendly user interface PgAdmin III. PostGIS 2.3 for PostgreSQL 9.5 was installed using the stack builder and a database connection was completed by specifying the login username, password and Port as set while installing PostgreSQL [10]. Various SQL queries were executed to create various tables for the database for the Web GIS for mass land valuation datasets. A connection to the QGIS was also done using the PostGIS plugin on the QGIS.

\section{Importing Shapefiles into the database}

All shapefiles created for the study area were converted to their corresponding relational tables in a PostgreSQL database. This was done to ensure performance of spatial analysis on data of the geographical objects. The conversion of shapefiles to PostgreSQL database tables were achieved by importing the shapefiles using the shapefile import/export manager plugin in PostGIS. The imported tables contain all the attributes of the shapefile including the coordinates and geometry that define each feature in the database. All vector layers for the entire study area were imported into a centralized database. A connection between PostGIS database to QuantumGIS was also done so as to ensure real time updates of the database through a configuration of the PostGIS plugin on QGIS 3.0.

\subsection{Web Portal Design and Development}

An open source GeoServer was used as a spatial data server for publishing spatial data and interactive mapping applications to the internet [11]. The GeoServer has excellent performance in terms of functionality and speed on processing large dataset. It runs on top of installed Apache, tomcat and PHP applications. The Hypertext Transfer Markup Language (HTML), PHP, javascript and CSS were used to design the WebGIS application.

\subsection{Development of the Geographic User Friendlier Interface}

Leaflets application programming interfaces (APIs) were used to develop a geographic and user friendlier interface for the web GIS platform. The designed interface was made in such a way that the user's interaction is simple and efficient in terms of accomplishing user goals. The interface allows the users to select and search the spatial database for the land parcels in order to view the required data. The user is also able to interact with the universal navigation tools such as zoom in, zoom out, and zoom to full extent to view the map at different scales and identification of different map features. Esri imagery and open street basemaps were also incorporated into the system to enhance spatial context of the study area in terms of data mapping and visualization on the web GIS portal. Figure 2 demonstrates the running view of developed Web GIS.

\subsection{System Testing and Implementation}

Each component of the WebGIS framework implemented both in the database 


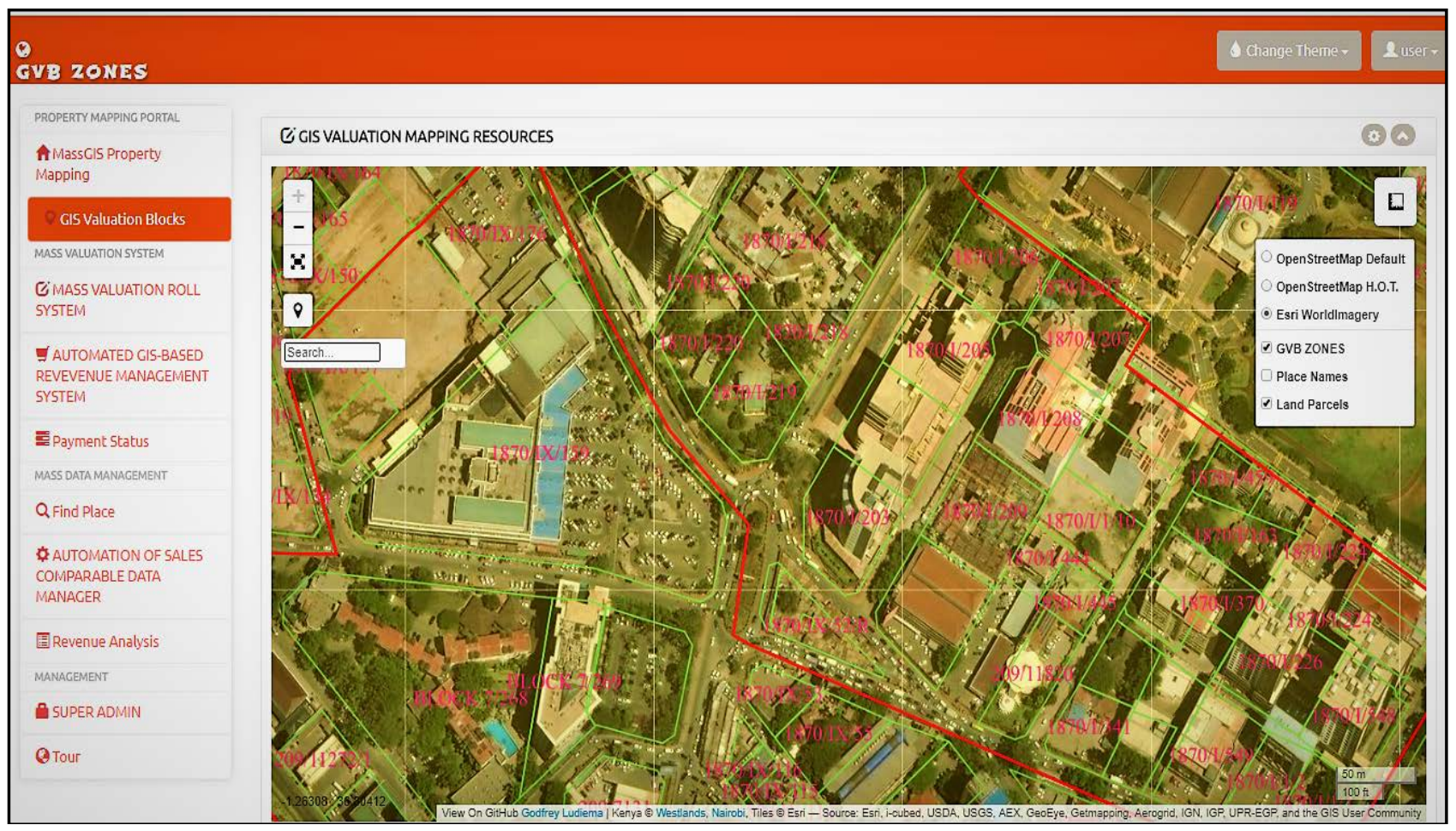

Figure 2. Running view of developed Web GIS portal.

and web application levels were tested. All the created relational tables were reloaded into the PostGIS database to test geometries of the vector datasets. In case the geometries are not created then such a table would not be drawn in GeoServer. As such the shapefile would be converted again until the geometries were created. The connection between the created spatial database and QGIS was also tested by making reconnection in QGIS then the chosen data layer in the database loaded into QGIS direct from the database. Edits on the vector data were done and then on saving the changes were directly effected in the relational table which is in turn interconnected to the GeoServer and the web application, hence change are reflected when displaying the data layer in Geoserver

\section{Results and Discussion}

\subsection{Web-Based Geographic Information System for Mass Property Valuation}

The prototype development is an internet-based Geographical Information System for managing mass land valuation roll for Westlands Constituency in Nairobi City County. It consists of three main tiers. First tier is an application server which is composed of an open source spatial enabled database system that is centralized for use by all users. Secondly, the client tier, a web-based mass GIS valuation system hosted on the main website in Figure 3 comprising of valuation modules for property mapping, geographic valuation blocks, an automated GIS-based revenue management system, payment status and an automated sales data management system. 


\subsubsection{Open Source Centralized Spatial Database}

Establishment of centralized mass property valuation database shown by section of the database in Table 3 improves reliability and update speed of the mass valuation roll. Centralized storage typically employs higher-quality components and redundancy, which makes it significantly more reliable than local storage. This database facilitates virtualization and provides comprehensive data access, if desired, from anywhere in the world by multiple users. Updates carried out on a database run on centralized storage carry through to all end-users, as opposed to local storage, which only applies to that computer which has been the case in Nairobi City County. This database ensures maximized data integrity and minimized data redundancy as the single storing place of all the data also implies that a given set of data only has one primary record. This aids in the maintenance of mass property valuation data as accurate and as consistent as possible and enhances data reliability in the city. The centralized mass valuation roll database also improves data security in managing vast quantities of sensitive county property owner information where data protection is a mission-critical issue. The central database creates and provides fewer challenges than ensuring data

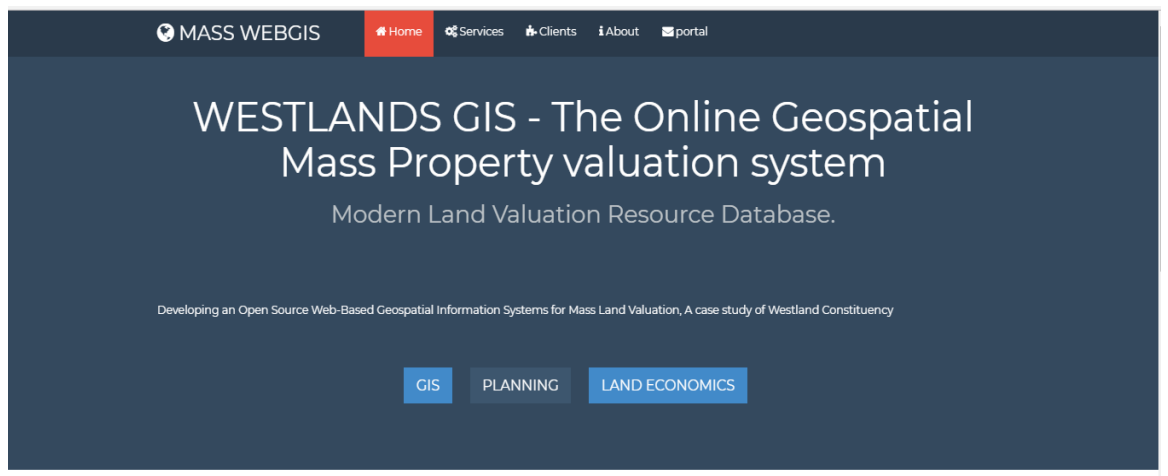

\section{Web-Based Geospatial Information System for Land Valuation}

Figure 3. Web-based geographic information system homepage.

Table 3. A section of mass land valuation roll database.

\begin{tabular}{ccccccccc}
\hline Plotno & Area M2 & Street & Mapno & Estate & Owner & GVB Code & GVB Rate & USV \\
\hline $1497 / 73$ & 1983.2 & Kiambu & MD60L90 & Karura & Oaker Ltd & GEO1020 & $19,901.00$ & $39,467,066.17$ \\
$1497 / 36$ & 1960.2 & Kiambu & MD60L90 & Karura & Stanley Kamani & GEO1020 & $19,901.00$ & $39,010,537.23$ \\
$1497 / 27$ & 1962.7 & Kiambu & MD60L90 & Karura & Daniel Mugambi & GEO1020 & $19,901.00$ & $39,060,488.74$ \\
$1497 / 28$ & 1960.5 & Kiambu & MD60L90 & Karura & Godfrey kabura & GEO1020 & $19,901.00$ & $39,015,313.47$ \\
$1497 / 33$ & 1959.1 & Kiambu & MD60L90 & Karura & Johnson Kasuti & GEO1020 & $19,901.00$ & $38,988,248.11$ \\
$1497 / 34$ & 1960.1 & Kiambu & MD60L90 & Karura & Stephen Musikar & GEO1020 & $19,901.00$ & $39,007,950.10$ \\
$1497 / 35$ & 1959.9 & Kiambu & MD60L90 & Karura & Joseth Munare & GEO1020 & $19,901.00$ & $39,004,367.92$ \\
$1497 / 7$ & 1971.7 & Kiambu & MD60L90 & Karura & Joseph Amunavi & GEO1020 & $19,901.00$ & $39,239,199.72$ \\
\hline
\end{tabular}


security across multiple local storage sites. Data access policies limit the data damage by implementing encrypted virtual private networks, firewalls and rigorous password protection on the mass valuation system. The mass valuation roll database is depended on an open source technology which makes it cheaper for Nairobi City County. The prepared centralized plot to plot inventory determines specific market value of each land parcel and identification the ownership of each piece of real property. The centralized database ensures easier data portability and database administration of land record and it provides a more cost effective approach in mass valuation of property in the city.

\subsubsection{Application Login of Users to the System}

To obtain access rights to the system users have to login using a registered username and password credentials shown in Figure 4. In order to have login credentials the system administrator needs to register a new user and provide the access credentials. The web portal has been used for the registration of users and for each login, the username and password credentials are validated to ensure secure login and prevention of unauthorized user access.

\subsection{Web GIS Viewer Interaction and Display}

The property mapping application in Figure 5 was designed to give various functional capabilities which are in build in the mapping system using various tools. The map window provides the user with a spatial view of parcel and valuation zones during the preceding valuation year. The map was compiled using a JavaScript map variable that drew on a collection of tiled map services and dynamic map services. Users can pan around the map by click-and-dragging or zoom in and out by using the scroll wheel on their mouse to increase or reduce the scale of the map so as to ease in locating features of interest and zoom to full extent can be used to view the whole map at the default minimum scale. More advanced users can also use the shift-select method to perform a targeted zoom into a specified area. The size of parcel of land on the map was designed to change depending on the scale of the map. One can view additional information

\section{SPATIAL LOG-IN SYSTEM}

\section{2}

godyludman@gmail.com|

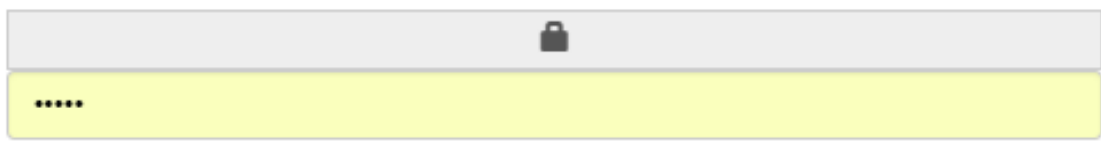

\section{SUBMIT}

Figure 4. Login portal on the web-based geographic information systems. 


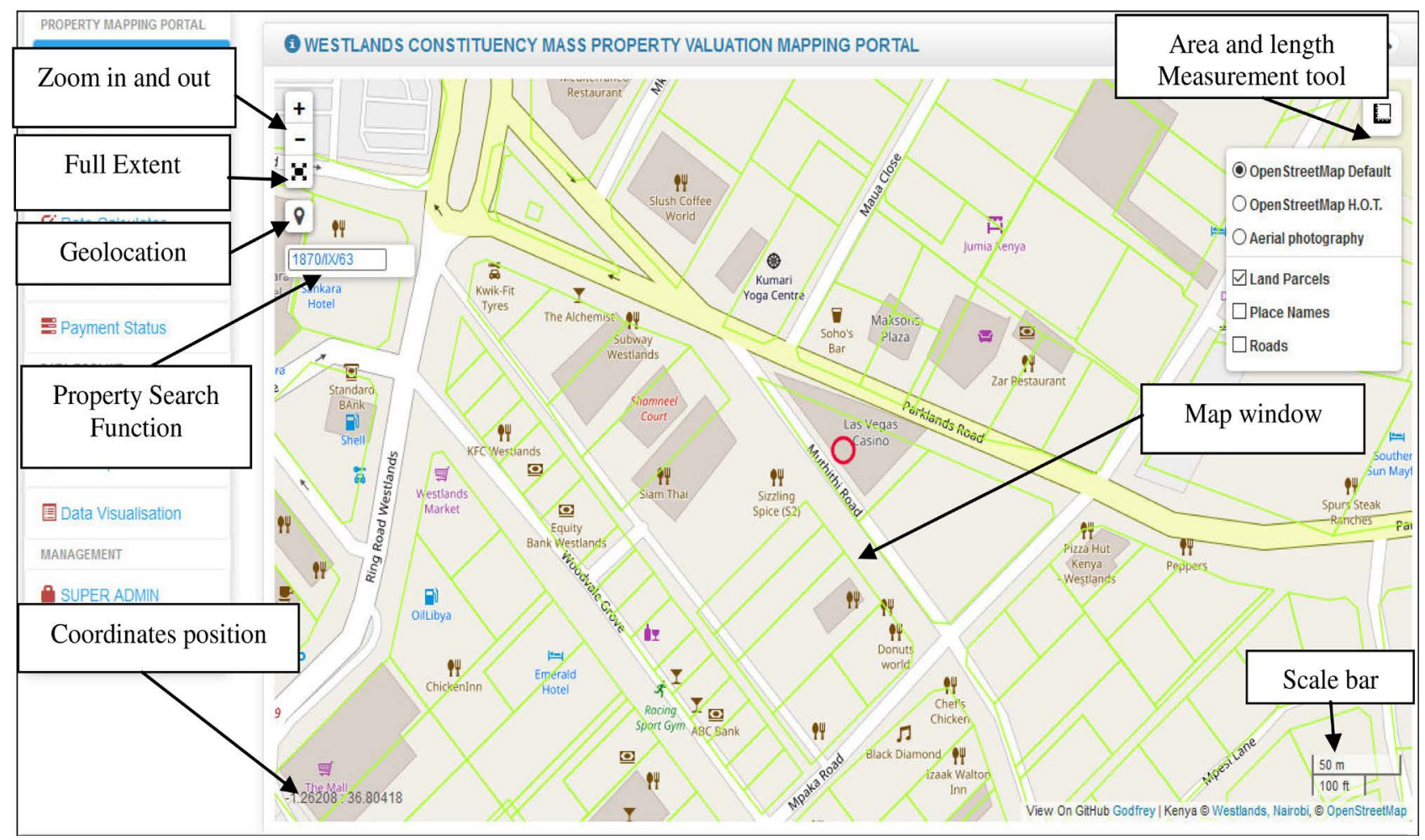

Figure 5. Navigation tools on the web-based geographic information systems.

for land parcels by single-clicking a feature polygon to create a popup window that displays descriptive information in the mass land valuation roll. The main mapping interface has the layer switcher which consists of various base maps and the valuation data for land parcels, place names and roads data. Within the Geographic Valuation Zones mapping web application, a user could also pan and zoom around a map using their mouse on a computer, or by utilizing a touch screen to pan and using the + and - icons to zoom. A location function is also available on both web applications that utilize the location services available on a device to approximate the user's current location.

\subsubsection{Automation of Property Searches and Data Retrieval}

GIS-based automation of property searches on the system enables the user to be able to search for specific property information using the parcel number from the centralized mass valuation roll database. The system user can use the search box to extract specific data related to a given feature and zooms to the specific position of parcel of interest. Data retrieval capability enables the user to obtain the associated land parcel attribute information like parcel number, parcel owner, area, street, estate, land value, geographic valuation code, map number, geographic valuation zonal rates and unimproved site value. This kind of information is very useful for property investors who would want to know all the above mentioned land attributes before making a sound decision on property transactions. Figure 6 shows the results of property search from the centralized database. 


\subsubsection{Area and Distance Measurements on the Web GIS}

The system enables users to carry out length and area measurement on the map using the length and area measurement tools respectively. The length can be measured in feets while the area measurements being measured in square feet and square miles. Current geographic positions on web map can be measured in terms of longitude and latitude in decimal degrees by clicking at the point of interest on the map. A green marker symbol appears where one has clicked on the map and its coordinates listed in the measure box in the chosen units. In Figure 7

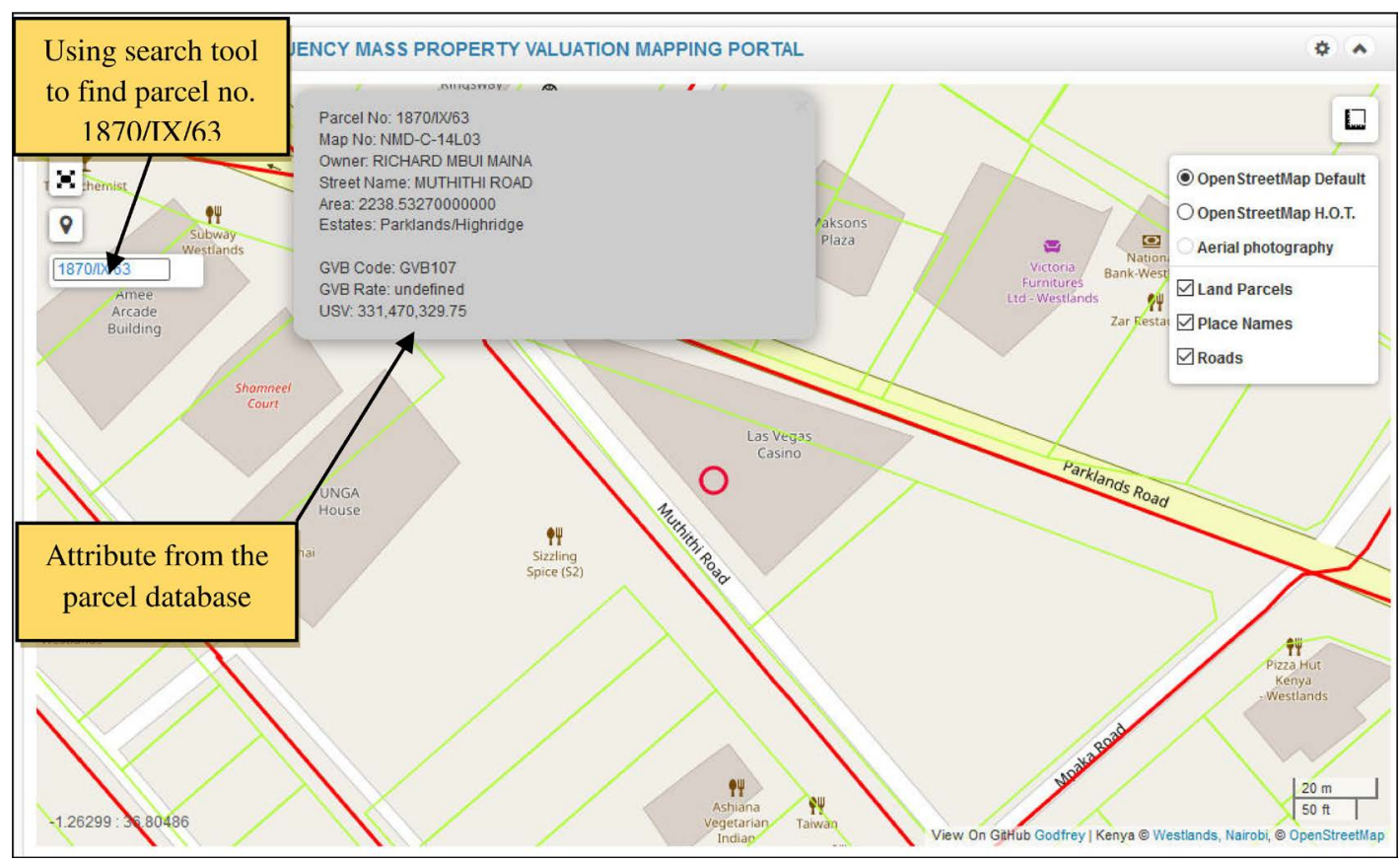

Figure 6. Automated property search capability for retrieving specific land parcel information.

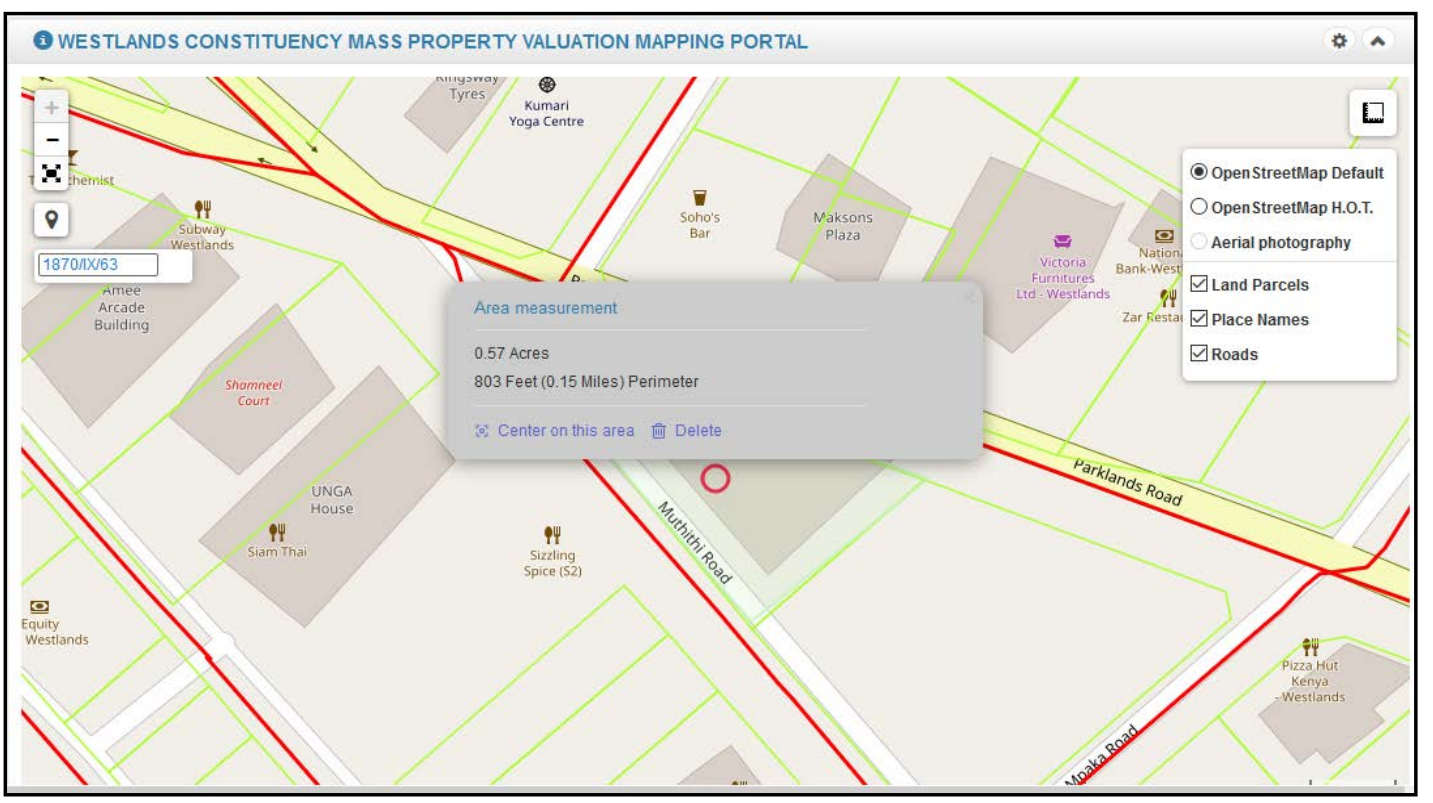

Figure 7. Length and area measurements functions on the Web-based GIS. 
shows the length and area measurements functions carries on the web map. This enables one to calculate the value of a property of the desired area size within a particular geographic valuation zone by making simple area measurement and the geographic valuation rates of the valuation zone or block. Property investors are able to know the value of a property regardless of the area size against other factors influencing the property value.

\subsection{Sub System of Web-Based Geographic Information System for Property Valuation}

The developed web-based Geographic Information System is made up of various sub systems that includes Mass GIS property mapping, GIS valuation block mapping, mass valuation roll system, Automated GIS-based Revenue Management system, payment status and an automated sales data management system as shown in Figure 8. The developed components of the web-based GIS collectively make up a GIS Assisted Mass Appraisal (GAMA) system because of it integrates GIS tools and Computer Assisted Mass Appraisals systems.

\subsubsection{GIS-Based Mass Valuation Roll Management System}

The entire system allows for full automation, continuous and timely updating of the mass valuation roll based on the geographic information system that is very efficient and effective in decision making on the properties valued. An up to date centralized database allows for optimal property taxation. The web-based GIS system allows for data exchanges between land valuation system, the land rates calculation and billing system. This reduces leakage and gives a more robust system for billing, payment, reconciliation and any other purposes as deemed

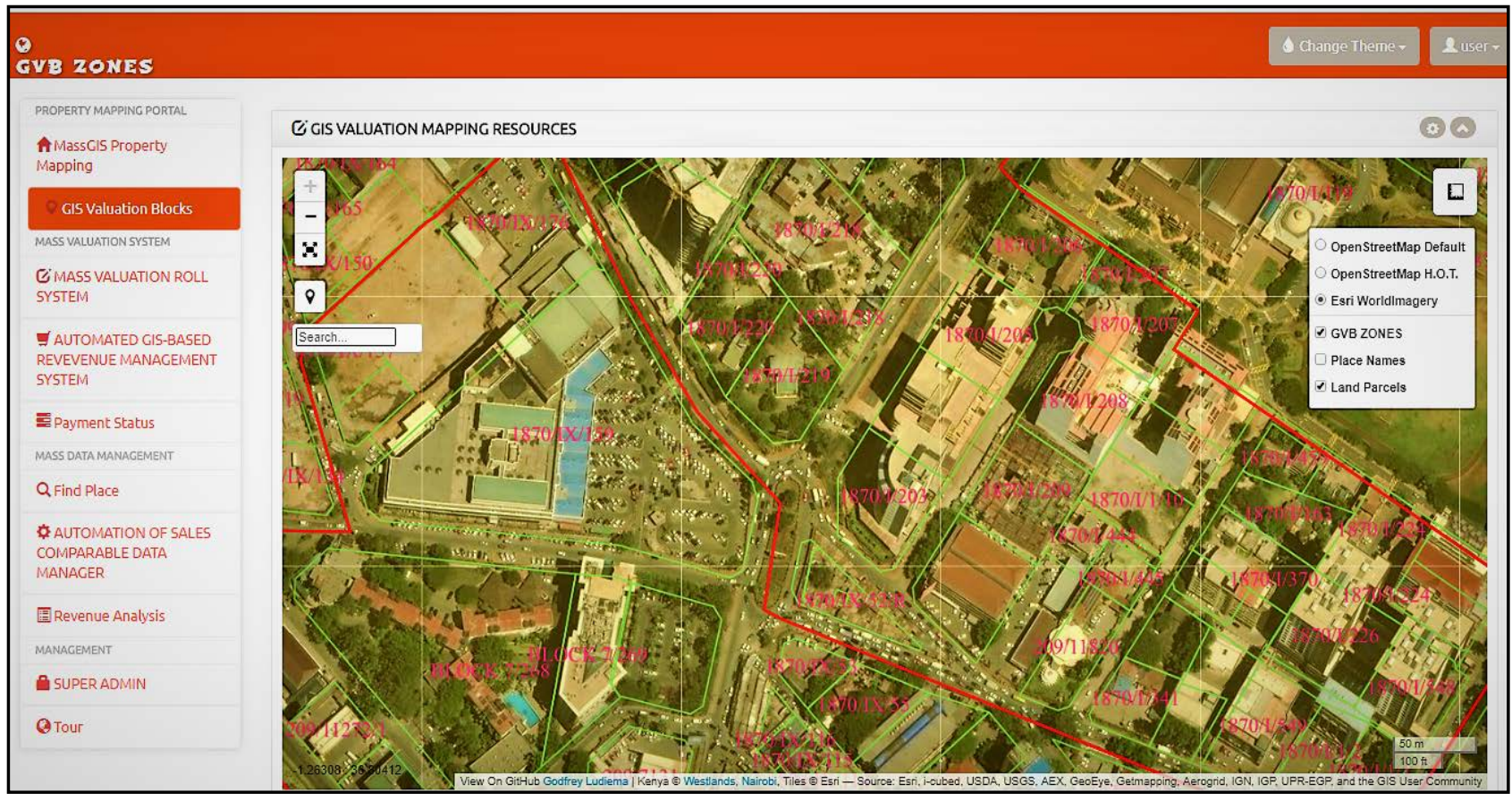

Figure 8. Components of the mass web-based geographic information systems. 
necessary. The user can be able to search the exact information from the valuation roll database using the mass valuation roll management system portal shown in Figure 9. The system also allows one to retrieve property taxes due based on the centralized database for mass land valuation. Land rates computations are automatically generated once the parcel number is inserted on the search box.

\subsubsection{Automated GIS-Based Revenue Management System}

The development of a GIS assisted mass appraisal system in this research can be used to optimize revenue collection from the property taxes of the valued properties based on an up-to-date centralized mass valuation roll database. The system in Figure 10 provides a solution by creating an electronic client and centralized property database for easy and reliable management of revenue resources from the property taxes. The property taxes can be monitored with the system on real time basis using a web-based GIS maps. Automation of revenue collection system boosts revenue E-enforcement through real time verification of the property tax payer records shown in Figure 11. The collected revenue can be used to provide services and infrastructure thus improving the lives of all the people in the county. This system supervises the timely collection and disposition of property taxes within the mass land valuation authority.

\subsubsection{Automation of Sales Comparable Data Management System}

The web GIS system enables valuers to collect data on valued property and sales of similar properties in the same neighborhood and even in different locations, including differences between property prices. It is possible to arrive at reasonably accurate estimates of land values over the whole valuation boundary. The

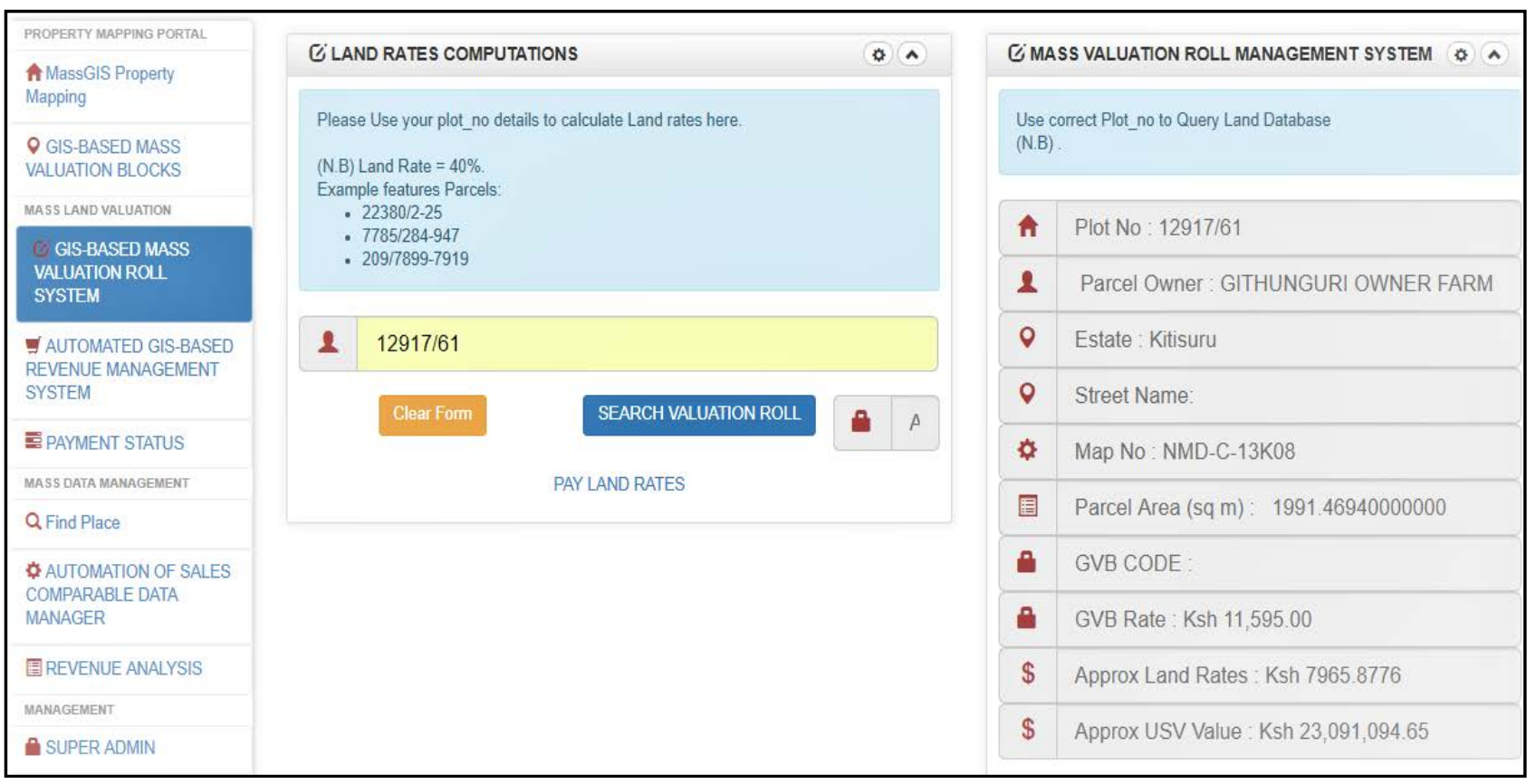

Figure 9. GIS-based mass valuation roll management system. 


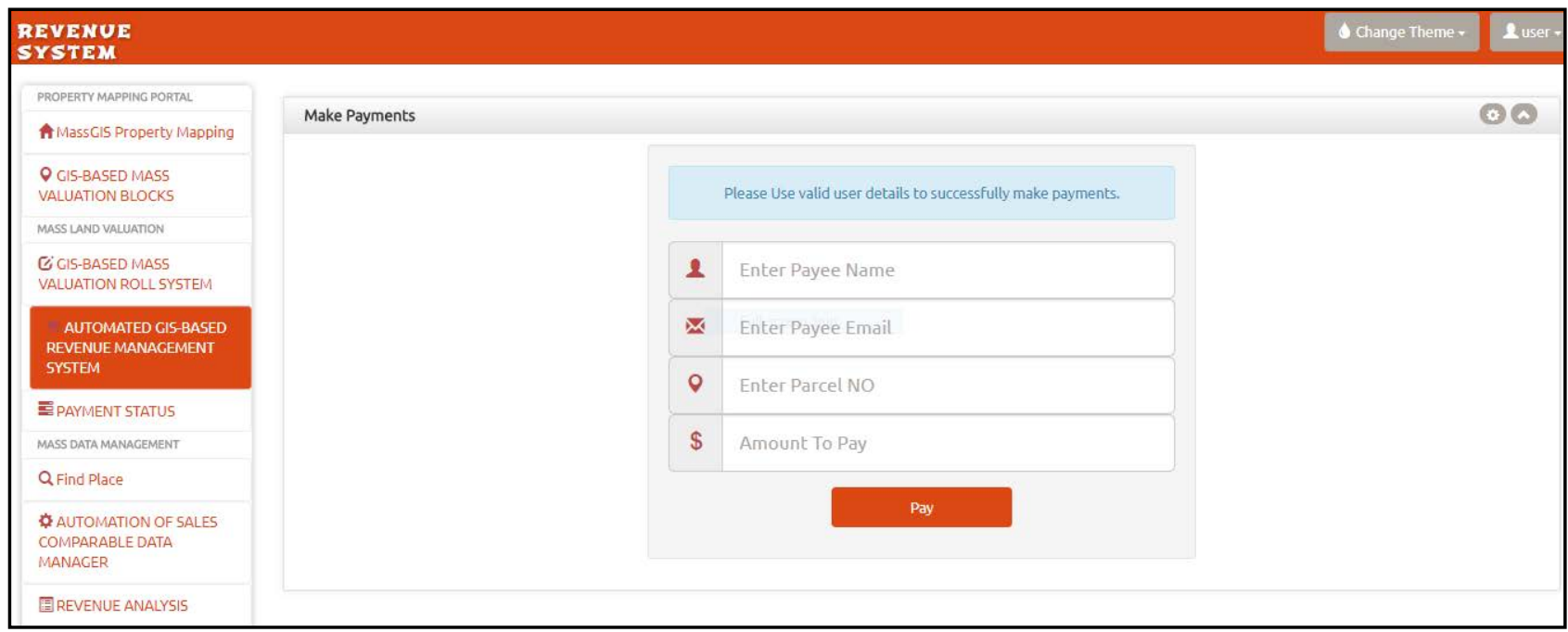

Figure 10. GIS-based revenue collection portal.

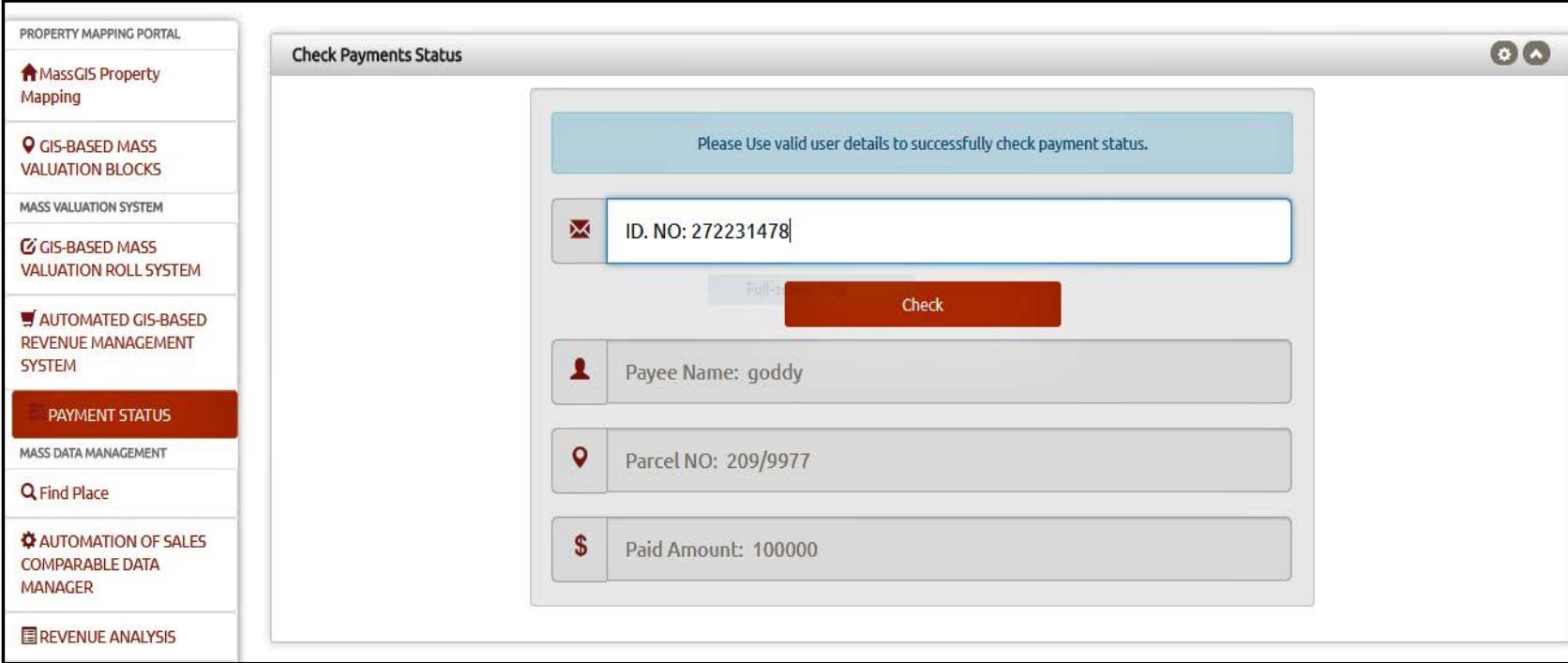

Figure 11. Verification of payment of property taxes paid.

data management system is a basically a field based information system for collecting the geographic valuation zonal values of properties by the valuer from the sales comparable of the recent property transactions. This automates the entire process of collecting sales comparable of properties which are then used to derive a GVB rate values that are applied to the land parcels within the valuation zone. All data on sales property transactions are collected using the web-based portal thus automating the entire system of mass land valuation for any county government or local authority. The parcel ownership information, land parcel number within the valuation authority, the GVB code, area, street, estate and the value for the sales comparable data is captured on the web-based GIS system. With the system the process of preparing mass valuation roll becomes very easy and cost effective, when it falls due, since all the data needed is be readily available in a centralized GIS-based database. Figure 12 shows the entire sales 


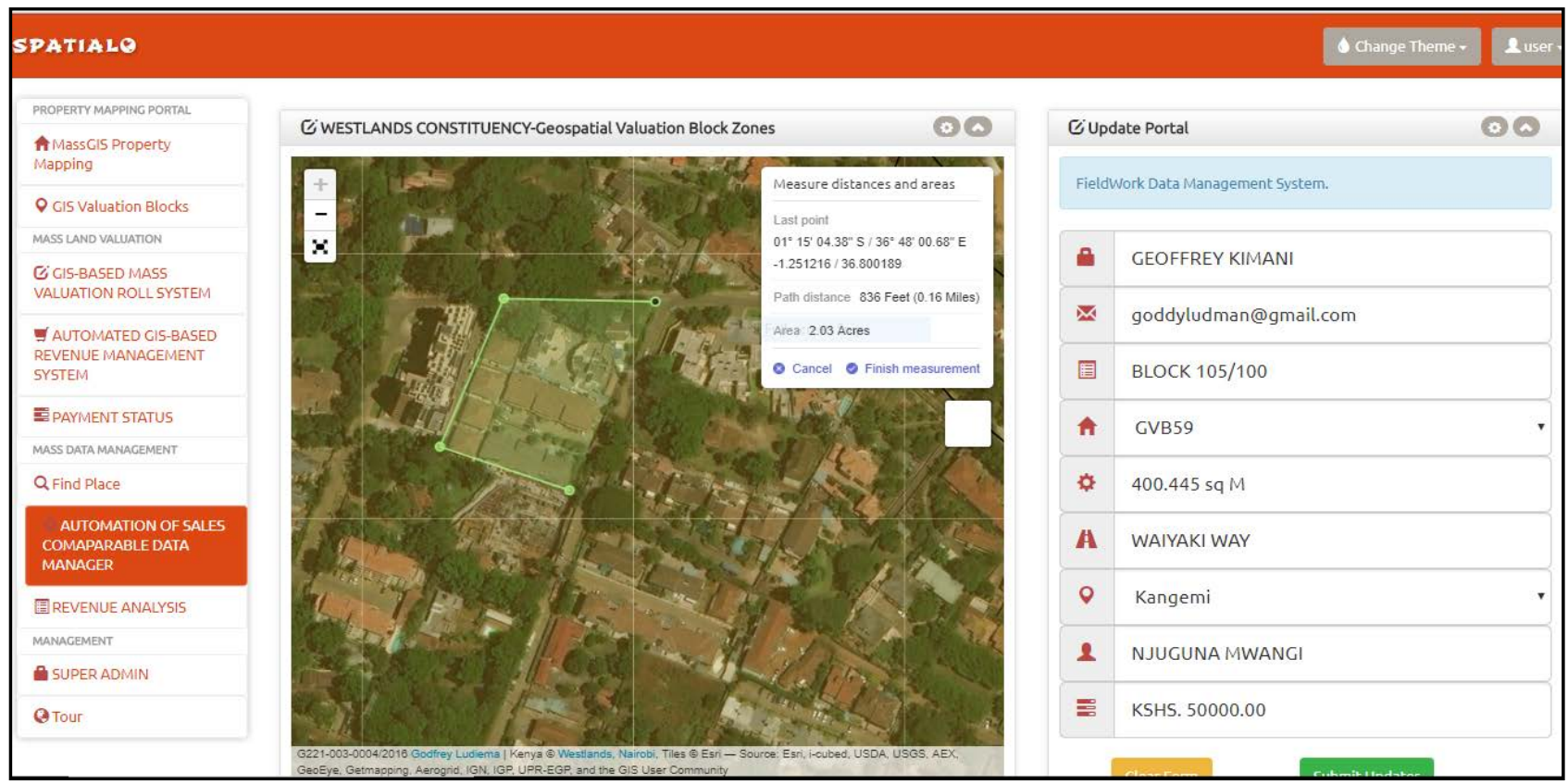

Figure 12. Automation of sales comparable data management system.

comparable data management and collection portal.

\subsection{User Needs Evaluation of the Web-Based GIS Application}

User feedback regarding the design of the web-based GIS application was collected. The participants in the survey were given an opportunity to interact with the web-based GIS application and there after they were asked a series of short answer and multiple choice questions which used five-tiered likert-item responses. Questions were designed to gauge how the user perceived the web application in terms of usability, web interaction and practicality. $88 \%$ of respondents found that the web application had an intuitive user interface and was easy to use as illustrated in Figure 13.

In Figure 14 40\% of respondents found that the inclusion of the zoom in and out tool on the web map was an effective tool for visualizing the land value map and valuation attributes, $27 \%$ of respondents were satisfied with the search function as it was effective in locating land parcel of interest on the web map. 13\% of the respondents also felt that basemap map control was a very important feature on the web map as it gave the map context of the mapping area for the mass land valuation. This tool gave the map context of the study area from open street maps and aerial photography. $8 \%$ of the respondents also found the full extent map control improved user interaction with the web-based GIS and only $1 \%$ of the respondent found geolocation as a vital tool for locating the user.

\section{Conclusion}

The study led to the development of a Web-based Geographical Information system for mass property valuation roll database. The system offered automation 


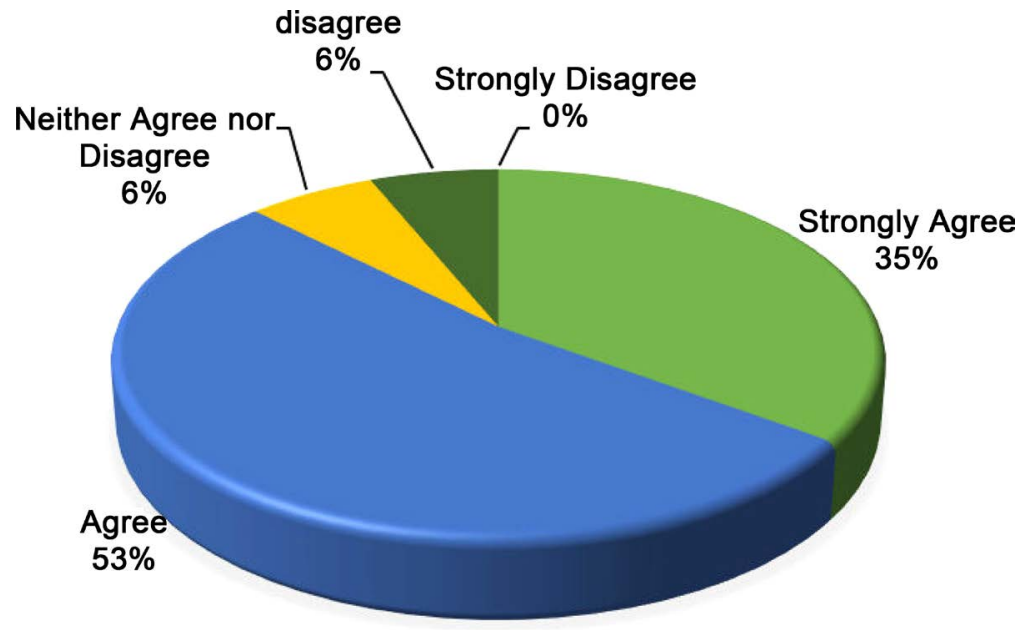

Figure 13. Intuitive user interface.

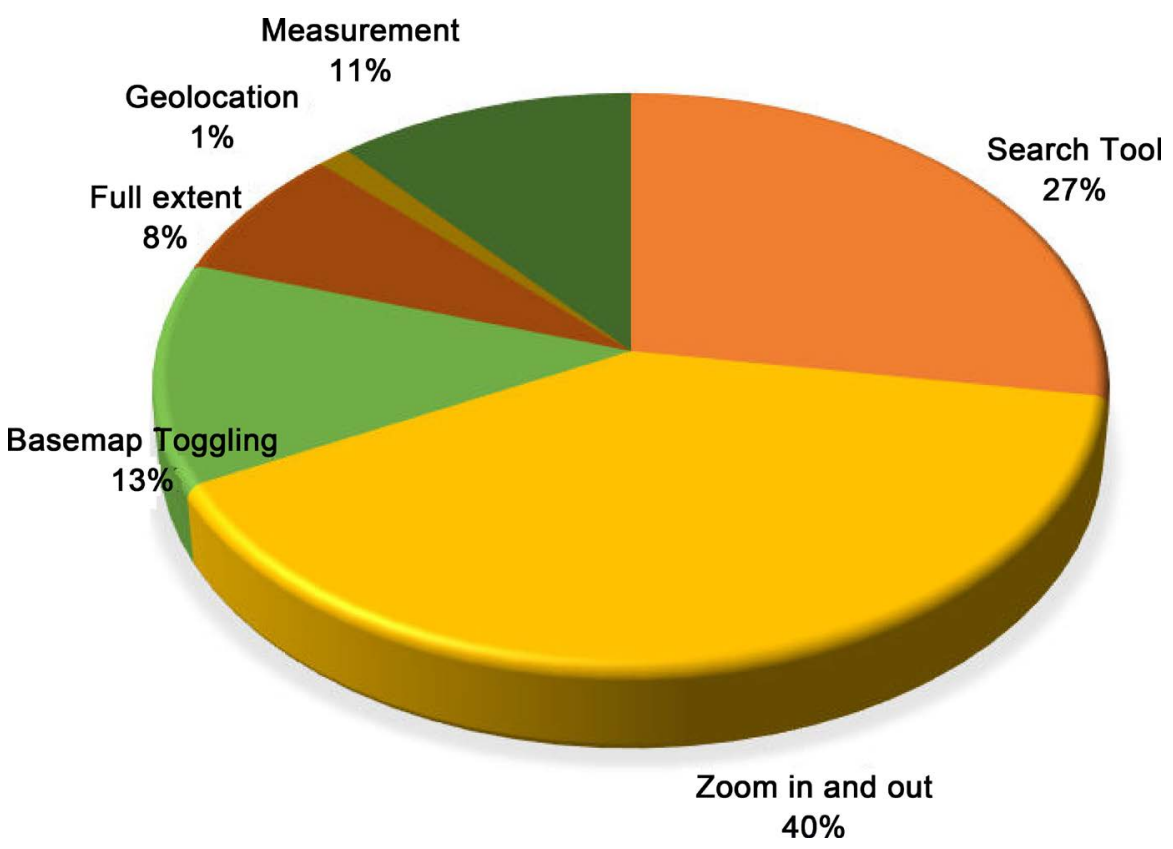

Figure 14. Effectiveness of the WebGIS functionality.

and management solutions to the mass property valuation roll, by providing one shared database hence reducing duplication and lowering maintenance cost. The web-based geographic information system for mass valuation ensures seamless property mapping across the valuation authority. The interactive property mapping component performs land searches, automates mass property valuation roll and updates of the database giving the property valuation authority and property viewers the desired results in a timely effective and efficient way. It enables developers, banks, realtors, businesses, and homeowners to view a seamless property and retrieve property tax information across the study area. The system also offered a mass property mapping interface that ensured Westlands Constituency leverages advancement in GIS technology in its service delivery. The system also offers a streamlined flow of land valuation information by having centralized 
database system accessible to all hence ensuring there is well structured process of collecting, storing and disseminating property valuation related information. From the study, one can draw conclusions that web-based GIS for mass land valuation is a prospective application in the geospatial world and it's an important advancement over the traditional desktop GIS. Its application eliminates duplication and inconsistency and makes location information conveniently and intuitively accessible across organizations, at a lower cost per user. The internet provides a medium for processing spatial information to users at an amount larger than traditional GIS. The study lays the foundation for proper management of a GIS-based mass valuation roll for optimal property taxation purposes. It aids in the realization of the Kenya Vision 2030 in developing an optimal revenue collection for the well-being of the city dweller in terms of service delivery. This research can be extended to create a nationwide GIS-based property valuation system for valuing all the available resources that can provide services for a wide range of users, starting with government institutions and ending with private individuals. Further improvements to the system could be made to include improved capabilities to carry out analysis using the available data. The system's functionality can also be improved such that it supports all of the procedures that are involved in the land administration like allocation of title deeds.

\section{Acknowledgements}

The authors wish to appreciate and thank staff at NCCG property valuation office and other stakeholders in the Ministry of Lands for the valuable data and cooperation for their invaluable input into the research.

\section{References}

[1] Deshmukh, M.H., Khare, R., Pandey, K. and Kumar, D. (2016) REIS: A Spatial Decision System for Land Valuation Indian Society of Geomatics. Journal of Geomatics, 10, 19-23.

[2] Yang, Y., Sun, Y., Li, S., Zhang, S., Wang, K., Hou, H. and Xu, S. (2015) A GIS-Based Web Approach for Serving Land Price Information. ISPRS International Journal of Geo-Information, 4, 2078-2093. https://doi.org/10.3390/ijgi4042078

[3] Dimopoulos, T. and Moulas, A. (2016) A Proposal of a Mass Appraisal System in Greece with CAMA System: Evaluating GWR and MRA Techniques in Thessaloniki Municipality. Open Geosciences, 8, 675-693. https://doi.org/10.1515/geo-2016-0064

[4] Government of Kenya (2013) Valuation and Local Government Rating Review.

[5] Neene, V. (2017) Development of a Mobile GIS Property Mapping Application Using Mobile Cloud Computing. International Journal of Advanced Computer Science and Applications, 8, 57-66. https://doi.org/10.14569/IJACSA.2017.081008

[6] Adamuscin, A. (2017) Real Estate Appraisal in Central-Eastern Europe: Comparative Analysis of Poland and Slovakia. The Journal of Towarzystwo Naukowe Nieruchomosci, 25, 50-62. https://doi.org/10.1515/remav-2017-0029

[7] Noor, N.M., Asmawi, M.Z. and Abdullah, A. (2015) Sustainable Urban Regeneration: GIS and Hedonic Pricing Method in Determining the Value of Green Space in Housing Area. Procedia-Social and Behavioral Sciences, 170, 669-679. 
https://doi.org/10.1016/j.sbspro.2015.01.069

[8] Shehu, E., Vorpsi, E.M. and Afezolli, A. (2015) Mass Valuation and the Implementation Necessity of GIS (Geographic Information System) in Albania. Journal of Civil Engineering and Architecture, 9, 1506-1512.

[9] QGIS (2018) http://www.qgis.org/

[10] PostgreSQL (2018) http://www.postgresql.org/

[11] Geoserver (2018) http://geoserver.org/ 